Research Article

\title{
Symbiosis Relationship and Symbiosis Quality Evaluation of Regional Tourism: A Case Study on the Greater Changbai Mountains Tourist Area
}

\author{
Yixuan $W u^{1}$ and Baoding Sun iD $^{2}$ \\ ${ }^{1}$ College of Chinese Medicinal Materials, Jilin Agricultural University, Changchun 130118, China \\ ${ }^{2}$ College of Economics and Management, Jilin Agricultural University, Changchun 130118, China \\ Correspondence should be addressed to Baoding Sun; sunbaoding@jlau.edu.cn
}

Received 2 September 2021; Revised 27 September 2021; Accepted 11 October 2021; Published 25 October 2021

Academic Editor: Daqing Gong

Copyright (C) 2021 Yixuan Wu and Baoding Sun. This is an open access article distributed under the Creative Commons Attribution License, which permits unrestricted use, distribution, and reproduction in any medium, provided the original work is properly cited.

\begin{abstract}
This paper aims to fully tap the value of the tourism brand of Changbai Mountains scenic area, give play to the radiation effect of the brand, and create the Greater Changbai Mountains (GCM) tourist area, thereby enhancing the coordinated development of regional tourism. Specifically, symbiosis correlation and symbiosis density were adopted to recognize the tourism symbiosis units in the core region of GCM tourist area, and an evaluation model was established for the tourism symbiosis quality in the core region of GCM tourist area. Based on the evaluation results, the places within the core region were divided into multiple levels. The results show that the core region of GCM tourist area covers Yanji City, Dunhua City, Hunchun City, Antu County, Baishan City, Fusong County, Changbai County, and Tonghua City, and these places fall on three different development levels.
\end{abstract}

\section{Introduction}

Proposed by the German biologist Heinrich Anton de Bary in 1879 , symbiosis means different organisms live together in a certain physical association [1]. With the development of research and practice, the symbiosis theory has been gradually extended to tourism development industry. In 1984, Stringer and Pearce [2] became the first to introduce this theory to tourism and advocated people-oriented tourism research. Taking collaborative tourism planning as an example, Getz and Jamal [3] analyzed the symbiosis relationship between environment and community. Later, many other scholars combined symbiosis theory with tourism research, making the latter more scientific and applicable.

Tourism symbiosis refers to the mutual promotion and joint development between destinations in the tourism market, with the goal to realize the coexistence, mutual sharing, reciprocity, and win-win between two or more parties [4]. However, foreign scholars emphasize empirical analysis over the theoretical system of tourism symbiosis, while domestic scholars mainly tackle the symbiosis relationship of regional tourism, stakeholders, and urban tourism.

$\mathrm{Wu}$ and $\mathrm{Gu}[5-8]$ analyzed the conditions of tourism development and tourism competition modes and measures in various regions, aiming to develop an integrated structure of regional tourism. Ji [9-11] studied the symbiosis relationship and symbiosis development of stakeholders of regional tourism and set up coordination mechanisms, shedding new lights on sustainable tourism development. $\mathrm{Ma}$ [12-14] took local governments, community residents, tourists, and travel agencies as objects and improved symbiosis models to support the harmonious coexistence between tourism stakeholders. Lu et al. [15-17] identified the symbiosis relationship between multiple urban tourism centers in Beijing-Tianjin-Hebei (BTH) region, from such three perspectives as energy level, external associations, and external functions. Yang [18] determined the spatial structure of multicenter symbiosis for regional tourism in Wuhan Metropolitan Area, according to the interaction intensity between symbiosis units, the connection of tourism 
economy, and symbiosis density. Using homogeneity, correlation, and external function intensity, Ma and Wang [19] discussed the tourism symbiosis of city clusters and put forward strategies for coordinated development.

For nearly a decade, symbiosis theory has been adopted for quantitative research of regional tourism. Quantitative analysis becomes a representative approach, using symbiosis degree and symbiosis coefficient. Later, correlation, symbiosis density, and external function intensity were introduced to study. It promotes the development of quantitative analysis of symbiosis theory and further applies symbiosis theory in regional tourism.

Changbai Mountains tourism is a first product of tourism in Jilin Province and the other two provinces in northeastern China (i.e., Liaoning and Heilongjiang). Since 2002, Ni and Wei $[20,21]$ have been calling for sustainable use and ecological protection in tourism resource development of Changbai Mountains. Focusing on ecotourism, the existing studies on Changbai Mountains tourism mainly advocate moderate development and rational protection and pursue the sustainable development of society, economy, environment, and culture [22-26]. The research scope is limited to the Changbai Mountains scenic area or Changbai Mountains Nature Reserve. Little consideration is given to the driving effect of Changbai Mountains on regional economy.

In recent years, Jilin Provincial Government, along with Changbai Mountains Protection Development Management Committee, reiterated their vision of building the Changbai Mountains Ecotourism Economic Circle, the Greater Changhai Mountains (GCM) Region, the destinations in the core region of Changhai Mountains, and the grand tourism pattern with Changbai Mountains at the core. In 2018, Jilin Province released the Layout Plan for "One Pillar, Six Pairs" Industrial Space, which defines the region of the province on the east of G1 Beijing-Harbin Expressway as an important functional area for the transition to ecological and green development. As the leading tourism brand in Jilin, Changbai Mountains should better lead the tourism development in the region. Therefore, this paper intends to identify the core region of GCM tourist area with the aid of symbiosis theory and provide the theoretical basis and suggestions for establishing GCM tourist area and the coordinated symbiosis development of its core region.

\section{Methodology and Data Sources}

Following the traditional analysis framework of symbiosis theory, this paper firstly identifies the symbiosis units with the strongest tourism economy correlations with Changbai Mountains as candidate areas and effectively selects the county/city-level tourism symbiosis units in the core region of GCM tourist area. Next, the symbiosis unit quality evaluation model was applied to evaluate the quality of each symbiosis unit in the core region. The evaluation results were clustered and divided into different levels. Finally, development directions were proposed according to the location and unique features of the units in the region.
2.1. Identification of Symbiosis Units. Correlation is an important metric of the relationship between symbiosis units. This paper measures tourism economy correlation $F_{i j}$ between each city of Jilin within Changbai Mountains and Changbai Mountains scenic area [27]:

$$
F_{i j}=G \frac{\sqrt{P_{i} G_{i}} \sqrt{P_{j} G_{j}}}{D_{i j}^{2}},
$$

where $G=1$ is the gravitational constant; $P_{i}$ is the number of tourists received by each city of Jilin within Changbai Mountains in 2012-2017 (unit: ten thousand person-times); $P_{j}$ is the number of tourists received by Changbai Mountains scenic area in 2012-2017 (unit: ten thousand person-times); $G_{i}$ is the tourism income of each city of Jilin within Changbai Mountains in 2012-2017 (unit: 100 million yuan); $G_{j}$ is the tourism income of Changbai Mountains scenic area in 2012-2017 (unit: 100 million yuan); and $D_{i j}$ is the time distance between two cities (unit: hour). The greater the $F_{i j}$ value, the closer the tourism economy correlation between each city of Jilin within Changbai Mountains and Changbai Mountains scenic area.

Symbiosis density mainly reflects the number of symbiosis units. In this paper, symbiosis density is determined by the economic action radius $R$ of each city, and the symbiosis units in the core region of GCM tourist area were identified by analyzing the economic action scope of the region [18]:

$$
\begin{aligned}
& R=\frac{\sqrt[4]{P G}}{\sqrt{C}}, \\
& r=\sqrt{\frac{S}{\pi}}
\end{aligned}
$$

where $P$ is the number of permanent residents; $G$ is the gross domestic product (GDP); $C \in[0.1,0.5]$ is the boundary field intensity of urban market (here, $C=0.1$ for urban economic action, and $C=0.5$ for core region); $S$ is the circle fitted for the actual area of each city, which facilitates the comparison of the actual area and economic action radius between cities; $r$ is the city radius; and $\pi=3.14$ is the circumference constant.

2.2. Quality Evaluation of Tourism Symbiosis Units. To promote the development of the Greater Changbai Mountains tourist area, it is necessary not only to determine the core areas for priority development, but also to clarify the similarities and differences between tourism symbiotic units. The higher the quality of tourism symbiotic unit, the greater the symbiotic gravitational force between tourism and other destinations. The evaluation index system for the quality of tourism symbiosis units involves two primary indices, namely, tourism economy scale and tourism symbiosis condition (Table 1) [28]. The tourism economic scale index mainly measures the tourism economic conditions of each symbiotic unit. The tourism symbiosis condition index mainly measures the symbiosis ability of each symbiosis 
TABLe 1: Evaluation index system for the quality of tourism symbiosis units.

\begin{tabular}{lccc}
\hline Primary indices & Secondary indices & Unit & Index direction \\
\hline \multirow{2}{*}{ Tourism economy scale } & Geographical scale, GS & $\mathrm{km}^{2}$ & Positive \\
& Tourism resource endowment, TRG & - & Positive \\
& Number of tourists, NT & 10,000 people & Positive \\
& Tourism income, TI & - & Positive \\
Tourism symbiosis condition & Width of symbiosis interface, S & - & Positive \\
& Attainable symbiosis level, A & Each & Positive \\
& Scale of potential symbiosis partners, N & Positive & - \\
\hline
\end{tabular}

unit. Therefore, by introducing the symbiotic unit quality model of tourism destination, the tourism core area of "the Greater Changbai Mountains" is classified, forming a purposeful and hierarchical tourism development of "the Greater Changbai Mountains."

The original data were processed through range standardization, and then, the indices were weighted by entropy method:

$$
\begin{aligned}
& \text { positive indices: } X_{i j}^{\prime}=\frac{\left[X_{i j}-\operatorname{MIN}\left(X_{j}\right)\right]}{\left[\operatorname{MAX}\left(X_{j}\right)-\operatorname{MIN}\left(X_{j}\right)\right]+0.01}, \\
& \text { negative indices: } X_{i j}^{\prime}=\frac{\left[\operatorname{MAX}\left(X_{j}\right)-X_{i j}\right]}{\left[\operatorname{MAX}\left(X_{j}\right)-\operatorname{MIN}\left(X_{j}\right)\right]+0.01},
\end{aligned}
$$

where $X_{i j}$ is the observation of object $i$ on index $j$ and $\operatorname{MAX}\left(X_{j}\right)$ and $\operatorname{MIN}\left(X_{j}\right)$ are the maximum and minimum of index $j$, respectively. To prevent negative values or zeros in nondimensionalization, 0.01 was added to every value. The standardized data are further calculated to clarify the dispersion degree of the objects to be evaluated under each index, and finally, the comprehensive weight of each index is obtained.

The quality evaluation of tourism symbiosis units intends to evaluate the size of tourism economy scale and the quality of tourism symbiosis condition in each destination. Hence, aggregative weighted index method was employed to build the tourism symbiosis quality index (TSQI) model:

$$
\begin{aligned}
\text { TESI }_{i} & =\beta_{11} \mathrm{GS}_{i}+\beta_{12} \mathrm{TRG}_{i}+\beta_{13} \mathrm{NT}_{i}+\beta_{14} \mathrm{TI}_{i}, \\
\text { TSCI }_{i} & =\beta_{21} S_{i}+\beta_{22} A_{i}+\beta_{23} N_{i}+\beta_{24} F_{i}, \\
\text { TSQI }_{i} & =\beta_{1} \mathrm{TESI}_{i}+\beta_{2} \mathrm{TSCI}_{i},
\end{aligned}
$$

where $\mathrm{TESI}_{i}$ is the tourism economy scale index; $\mathrm{GS}_{i}, \mathrm{TRG}_{i}$, $\mathrm{NT}_{i}$, and $\mathrm{TI}_{i}$ are the observations of the geographical scale, tourism resource endowment, number of tourists, and tourism income of symbiosis unit $i$, respectively; $\mathrm{TSCI}_{i}$ is the tourism symbiosis condition index; $S_{i}, A_{i}, N_{i}$, and $F_{i}$ are the observations of the width of symbiosis interface, attainable symbiosis level, scale of potential symbiosis partners, and symbiosis index of symbiosis unit $i$, respectively; TSQI $_{i}$ is the composite quality index of symbiosis unit $i ; \beta_{1}$ and $\beta_{2}$ are the weights of TESI and TSCI, respectively; $\beta_{11}, \beta_{12}, \beta_{13}$, and $\beta_{14}$ are the weights of GS, TRG, NT, and TI, respectively $\left(\beta_{11}+\beta_{12}+\beta_{13}+\beta_{14}=1\right)$; and $\beta_{21}, \beta_{22}, \beta_{23}$, and $\beta_{24}$ are the weights of $S, A, N$, and $F$, respectively $\left(\beta_{21}+\beta_{22}+\beta_{23}+\beta_{24}=1\right)$.
2.3. Data Sources. The research data were obtained in the following steps: First, some data were collected from official websites of local governments, including geographic information websites, regional statistics websites, and the websites of local culture, radio, television, and tourism administrations. Second, some data were acquired from the statistical yearbooks 2015-2019 in each city and the statistical bulletins of national economic and social development 2014-2018 in each city. Third, the missing data were obtained through field surveys. Finally, online data were queried and screened using Baidu Index, qunar.com, and so on. Different formats and different types of collected data are unified data standardization processing and then calculation and comparison.

\section{Research Results}

3.1. Overview of the Study Area. In the broad sense, Changbai Mountains refer to all the mountains in the east of northeastern China. Seven prefectures in Jilin Province belong to the range of Changbai Mountains in this sense, including Changchun Prefecture, Jilin Prefecture, Siping Prefecture, Liaoyuan Prefecture, Tonghua Prefecture, Baishan Prefecture, and Yanbian Korean Autonomous Prefecture (hereinafter referred to as Yanbian Prefecture).

In the narrow sense, Changbai Mountains stand for Changbai Mountains Nature Reserve or Changbai Mountains scenic area. The specific range depends on research contents. Located in the southeast of Jilin Province, Changbai Mountains Nature Reserve spans across Antu County, Fusong County, and Changbai Korean Autonomous County (hereinafter referred to as Changbai County). Changbai Mountains scenic area consists of three scenic spots: northern slope, western slope, and southern slope. The latest data show that the northern, western and southern slopes have received 251 million tourists, up by $4.1 \%$ yearon-year. Among the travel routes in Jilin Province, 93\% are related to Changbai Mountains scenic area. Figure 1 shows the tourism economy data of Changbai Mountains scenic area in the past five years.

\subsection{Identification of Tourism Symbiosis Units in the Core} Region of GCM. The mean gravity of the seven prefectures of Jilin in the range of Changbai Mountains was calculated as 3.02 using formula (1). Among them, Baishan Prefecture, Tonghua Prefecture, and Yanbian Prefecture had above-the-average gravities. Hence, it is feasible to build GCM tourist area based on the eastern part of Jilin and Changbai Mountains scenic area. 


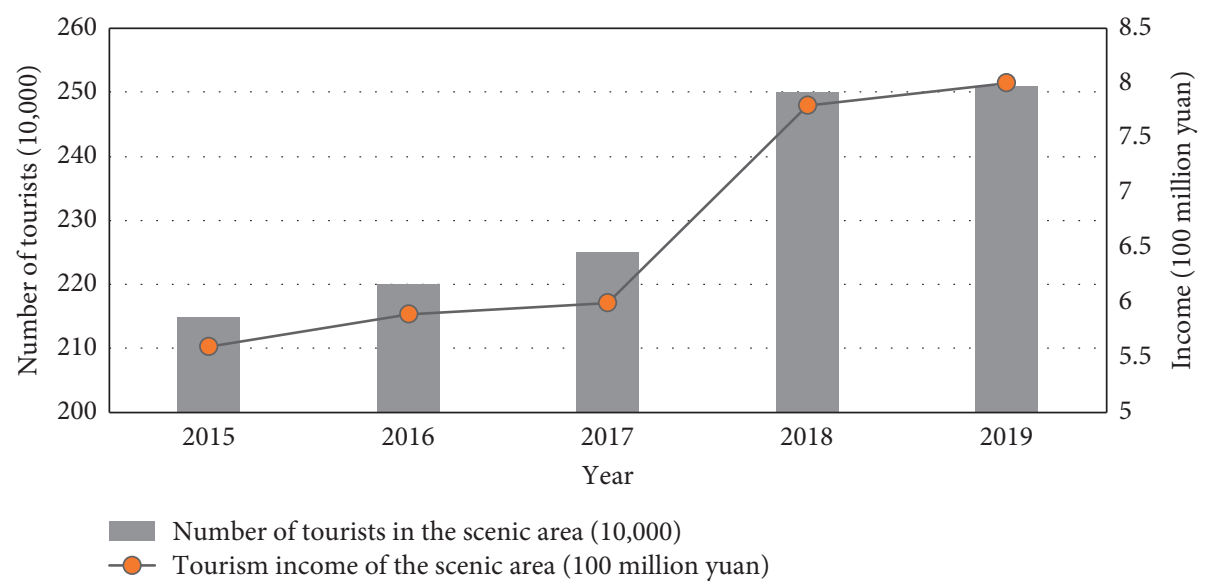

FIgURE 1: Tourism statistics of Changbai Mountains scenic area.

Baishan Prefecture had the strongest tourism economy correlation with Changbai Mountains scenic area, which, to a certain extent, reflects the proximity effect between the two places. This is attributable to the resource advantages of Baishan Prefecture.

Siping Prefecture had the weakest tourism economy correlation with Changbai Mountains scenic area. The main reason is the long distance between the prefecture and the scenic area. Despite falling within the range of the mountains, Siping Prefecture receives a weak tourism economy radiation, due to the long distance and inconvenient transportation. Therefore, this prefecture was excluded from the core region of GCM tourist area.

The tourism economy radiation of Changbai Mountains scenic area greatly influences the tourism development in Tonghua Prefecture, Baishan Prefecture, and Yanbian Prefecture. The specific symbiosis relationships are listed in Table 2.

Changbai Mountains scenic area covers Antu County, Fusong County, and Changbai County. These counties serve as connecting links in tourism development. The symbiosis densities were measured for the 21 counties/cities in Baishan Prefecture, Tonghua Prefecture, and Yanbian Prefecture using formulas (2) and (3).

The results show that, in six counties/cities, namely, Yanji City, Dunhua City, Huichun City, Baishan City, Fusong County, and Tonghua City, the core region area was greater than the mean of $23.82 \mathrm{~km}$, and the action radius was larger than the mean of $10.65 \mathrm{~km}$. Hence, the economic action of the six counties/cities impacts a much larger scope than that of the remaining ten counties/cities. Among them, Yanji City, Baishan City, and Tonghua City had relatively large radiation scopes. These three symbiosis units are the political and economic centers of Yanbian Prefecture, Baishan Prefecture, and Tonghua Prefecture, respectively. As a result, they are superior to other tourism symbiosis units in geographic location, economic development, and transportation convenience. The tourism economy radiation in the surrounding areas directly affects the development of the core region of GCM tourist area.

In the formation and development of the symbiotic system, the symbiotic unit cannot increase indefinitely. When
TABle 2: Symbiosis correlation between each prefecture and Changbai mountains scenic area.

\begin{tabular}{lccccccc}
\hline \multirow{2}{*}{\begin{tabular}{lcccccc}
\multicolumn{7}{c}{ Attraction } \\
\end{tabular}} & 2017 & 2016 & 2015 & 2014 & 2013 & 2012 & \\
\hline Changchun & 4.68 & 3.36 & 2.45 & 1.76 & 1.29 & 0.44 & 2.33 \\
$\begin{array}{l}\text { Prefecture } \\
\text { Jilin Prefecture }\end{array}$ & 4.50 & 3.31 & 2.43 & 1.72 & 1.25 & 0.43 & 2.27 \\
Siping Prefecture & 3.54 & 2.42 & 1.66 & 1.20 & 0.88 & 0.30 & 1.66 \\
Liaoyuan & 4.92 & 3.39 & 2.48 & 1.78 & 1.31 & 0.44 & 2.39 \\
Prefecture & & & & & & & \\
Tonghua Prefecture & 7.43 & 5.15 & 3.76 & 2.68 & 1.96 & 0.67 & 3.61 \\
Baishan Prefecture & 11.16 & 7.79 & 5.71 & 4.06 & 2.96 & 1.00 & 5.45 \\
Yanbian Prefecture & 6.92 & 4.95 & 3.59 & 2.52 & 1.84 & 0.71 & 3.42 \\
\hline
\end{tabular}

it exceeds a certain geographical range and the radiation range of tourism economy, the scale effect formed by the tourism symbiotic unit is lower, so a reasonable density of symbiotic unit must be selected. In this paper, the three cities with the strongest association with Changbai Mountain scenic area are selected as the core tourism area of the Greater Changbai Mountains. After that, it will be further expanded to radiate the whole Jilin Province. The density of symbiotic units is influenced by time, distance, element flow level, and other factors. Antu County and Changbai County are bordered with Chibei District and Chinan District of Changbai Mountains scenic area, respectively. The geographical location blesses these two symbiosis units with a certain symbiosis effect, and these two symbiotic units are also the tourist distribution center of Changbai Mountain scenic spot. Therefore, eight counties/cities were selected from Baishan Prefecture, Tonghua Prefecture, and Yanbian Prefecture, including Yanji City, Dunhua City, Huichun City, Antu County, Baishan City, Fusong County, Changbai County, and Tonghua City, as the core region of GCM tourist area. The symbiosis densities of these places are listed in Table 3.

3.3. Quality Evaluation of Tourism Symbiosis Units in the Core Region of GCM Tourist Area. To realize tourism symbiosis in the core region of GCM tourist area, it is important to compare the similarities and differences between symbiosis 
TABLE 3: Symbiosis densities of counties/cities in the core region of GCM tourist area.

\begin{tabular}{|c|c|c|c|c|c|c|c|}
\hline \multicolumn{2}{|c|}{ Administrative region } & $\begin{array}{l}\text { Area } \\
\left(\mathrm{km}^{2}\right)\end{array}$ & $\begin{array}{l}\text { Radius } \\
(\mathrm{km})\end{array}$ & $\begin{array}{c}\text { GDP (100 million } \\
\text { yuan) }\end{array}$ & $\begin{array}{c}\text { Permanent residents } \\
(10,000)\end{array}$ & $\begin{array}{c}\text { Core region } \\
\text { area }\end{array}$ & $\begin{array}{c}\text { Economic action } \\
\text { radius }\end{array}$ \\
\hline \multirow{7}{*}{$\begin{array}{l}\text { Yanbian } \\
\text { Prefecture }\end{array}$} & Yanji City & $1,748.3$ & 23.59 & 336.42 & 55.00 & 36.88 & 16 \\
\hline & Tumen City & $1,142.65$ & 19.07 & 21.99 & 11.28 & 12.55 & 6 \\
\hline & Dunhua City & 1,1957 & 61.69 & 181.41 & 46.02 & 30.23 & 14 \\
\hline & Helong City & $5,068.62$ & 40.17 & 59.90 & 31.50 & 20.84 & 9 \\
\hline & Huichun City & 5,141 & 40.45 & 144.58 & 22.88 & 23.98 & 11 \\
\hline & $\begin{array}{l}\text { Wangqing } \\
\text { County }\end{array}$ & 9,016 & 53.57 & 68.28 & 22.17 & 19.72 & 9 \\
\hline & Antu County & 7,444 & 48.68 & 75.00 & 20.94 & 19.91 & 9 \\
\hline \multirow{5}{*}{$\begin{array}{l}\text { Baishan } \\
\text { Prefecture }\end{array}$} & Baishan City & $2,725.5$ & 29.45 & 354.61 & 53.79 & 37.16 & 17 \\
\hline & Linjiang City & $3,008.5$ & 30.95 & 100.54 & 15.65 & 19.92 & 9 \\
\hline & Fusong County & 6,159 & 44.28 & 195.00 & 28.58 & 27.32 & 12 \\
\hline & Jiingyu County & $3,094.4$ & 31.38 & 73.00 & 13.60 & 17.75 & 8 \\
\hline & $\begin{array}{l}\text { Changbai } \\
\text { County }\end{array}$ & $2,497.6$ & 28.20 & 44.81 & 8.634 & 14.02 & 6 \\
\hline \multirow{4}{*}{$\begin{array}{l}\text { Tonghua } \\
\text { Prefecture }\end{array}$} & Tonghua City & $4,545.2$ & 38.04 & 261.85 & 55.37 & 34.70 & 16 \\
\hline & Ji'an City & $3,354.9$ & 32.68 & 86.85 & 21.57 & 20.80 & 9 \\
\hline & Huinan County & 2,275 & 26.91 & 80.88 & 37.00 & 23.39 & 10 \\
\hline & Liuhe County & $3,348.3$ & 32.65 & 57.56 & 40.00 & 21.90 & 10 \\
\hline
\end{tabular}

units, in addition to identifying these units. The higher the quality of the symbiotic unit of the tourist destination, the greater the gravitational force generated between the tourist destination and other tourist destinations. This paper evaluates the quality of each symbiosis unit in the core region, using the symbiosis unit quality evaluation model. The index data of each symbiotic unit are brought into the symbiotic unit quality model to obtain the symbiotic unit quality index and each subindex of tourist destination. The evaluations were clustered on ArcGIS, laying the basis for categorizing the cities in the core region. Tables 4 and 5 show the results of quality evaluation of tourism symbiosis units in the core region of GCM tourist area, which are obtained by formulas (4) and (5).

The quality of a symbiosis unit (destination) is positively correlated with the intensity of the symbiosis gravity field between the destination and other destinations. The results show that symbiosis units differed significantly in quality: the highest TSQI (Yanji City) was 0.7292 above the lowest TSQI (Changbai County).

The mean TSQI of the symbiosis units stood at 0.4519 . The TESIs of these units averaged 0.3913 , and the TSCIs of these units averaged 0.5206. Yanji City, which ranked the first in all three indices, was 15 times higher in TSQI, 12 times higher in TESI, and 20 times higher in TSCI, than Changbai County, which ranked the last in all three indices. The large gap of extreme values reflects the obvious imbalance of symbiosis unit quality in the core region of CGM tourist area.

To realize coordinated symbiosis in the region, the symbiosis units should maintain high quality indices and improve low quality indices. Therefore, the symbiosis units in the core region of CGM tourist area need to be clustered by symbiosis quality and divided into different levels. In this way, the core region could take pertinent and hierarchical measures to achieve coordinated symbiosis of regional tourism. The clustering results are given in Figure 2.
3.3.1. Changbai County. Named after Changbai Mountains, Changbai County is the only Korean autonomous county in China. This borderland of Jilin Province is open to the outside world. It is radiated by the Changchun-Jilin-Tumen Pilot Area of Development and Opening. On the southern slope of Changbai Mountains scenic area, Changbai County owns a national 4A scenic spot (Wangtiane scenic spot) and several national 3A scenic spots (Changbai Korean Folk Village, Changbai Port scenic spot, and Lingguang Tower scenic spot).

Albeit its unique tourism resources and superior location, Changbai County performed poorly in TESI (0.0564) and TSCI (0.0472) and thus came at the bottom of the TSQI ranking (0.0521). Compared with other tourism symbiosis units, Changbai County faces a low development level of tourism resources, poor tourism infrastructure, and severe demand-supply imbalance. The county needs to invest more in infrastructure and soft environment of tourism.

Changbai Mountains scenic area, which lies right next door, diverts the tourist flows and attention away from Changbai County. Hence, this county has a more urgent need for coordinated symbiosis than anywhere else in the core region of GCM tourist area. Changbai County should make full use of its unique resources and location advantages (the hinterland of Changbai Mountains and the source of Yali River), improve tourism infrastructure, and create a comprehensive service base in the south of Changbai Mountain scenic area. The county should position itself as a destination of all-for-one tourism and border tourism, turn the shadow effect of Changbai Mountains scenic area into radiation effect, and pursue mutual development with other symbiosis units.

3.3.2. Yanji City. Yanji City is a top-ranking city in Jilin Province, only behind Changchun Prefecture, and Jilin Prefecture. It is the geographical center of the six 
TABle 4: Symbiosis unit quality evaluation model.

\begin{tabular}{lccc}
\hline Serial number & Index & Weight symbol & Weight value \\
\hline 1 & Tourism economy scale index, TESI & $\beta_{1}$ & 0.5317 \\
$1-1$ & Geographical scale, GS & $\beta_{11}$ & 0.2975 \\
$1-2$ & Tourism resource endowment, TRG & $\beta_{12}$ & 0.1527 \\
$1-3$ & Number of tourists, NT & $\beta_{13}$ & 0.2187 \\
$1-4$ & Tourism income, TI & $\beta_{14}$ & 0.3310 \\
2 & Tourism symbiosis condition index, TSCI & $\beta_{2}$ & 0.4683 \\
$2-1$ & Width of symbiosis interface, $S$ & $\beta_{21}$ & 0.3652 \\
$2-2$ & Attainable symbiosis level, $A$ & $\beta_{22}$ & 0.1748 \\
$2-3$ & Scale of potential symbiosis partners, $N$ & $\beta_{23}$ & 0.1328 \\
$2-4$ & Symbiosis index, $F$ & $\beta_{24}$ & 0.3272 \\
\hline
\end{tabular}

TABle 5: Symbiosis unit quality index and subindices.

\begin{tabular}{lcccccc}
\hline Place & $\begin{array}{c}\text { Tourism } \\
\text { economy scale } \\
\text { index (TESI) }\end{array}$ & $\begin{array}{c}\text { Tourism } \\
\text { symbiosis } \\
\text { condition index } \\
\text { (TSCI) }\end{array}$ & \multicolumn{2}{c}{$\begin{array}{c}\text { Tourism } \\
\text { symbiosis } \\
\text { quality index } \\
\text { (TSQI) }\end{array}$} \\
& Score & Ranking & Score & Ranking & Score & Ranking \\
\hline $\begin{array}{l}\text { Yanji City } \\
\text { Dunhua }\end{array}$ & 0.6528 & 1 & 0.9270 & 1 & 0.7812 & 1 \\
$\begin{array}{l}\text { City } \\
\text { Huichun }\end{array}$ & 0.5607 & 2 & 0.4754 & 7 & 0.5208 & 2 \\
$\begin{array}{l}\text { City } \\
\begin{array}{l}\text { Antu } \\
\text { County }\end{array}\end{array}$ & 0.3025 & 7 & 0.4938 & 6 & 0.3921 & 7 \\
$\begin{array}{l}\text { Baishan } \\
\text { City }\end{array}$ & 0.4817 & 3 & 0.5592 & 3 & 0.5180 & 3 \\
$\begin{array}{l}\text { Fusong } \\
\text { County }\end{array}$ & 0.3071 & 6 & 0.5991 & 2 & 0.4438 & 6 \\
$\begin{array}{l}\text { Changbai } \\
\text { County }\end{array}$ & 0.0564 & 8 & 0.0472 & 8 & 0.0521 & 8 \\
$\begin{array}{l}\text { Tonghua } \\
\text { City }\end{array}$ & 0.3861 & 4 & 0.5346 & 4 & 0.4557 & 4 \\
\hline
\end{tabular}

northeastern Asian countries: China, Russia, Japan, Mongolia, North Korea, and South Korea. Situated in the hinterland of Northeast Asia economic circle, Yanji plays a key role in the tourism development of ChangchunJilin-Tumen Pilot Area of Development and Opening.

With the highest TESI (0.6528) and TSCI (0.9270) in the core region, Yanji City is critical to regional symbiosis. The city could utilize its advantages in geographical location, Korean folk culture, and cool summer to develop shopping tourism, folk tourism, gourmet tourism, and summer tourism.

Yanji City used to be the tourist distribution center of Changbai Mountains scenic area. However, the tourist distribution effect is weakened by the improving tourism and transportation infrastructure across Jilin Province. Therefore, Yanji City should rely on favorable policies (Changchun-Jilin-Tumen Pilot Area of Development and Opening and Revitalization of the Old Industrial Bases in Northeast China) and the joint marketing of the core region of Changhai Mountains tourist area, trying to complete the shift to integrated tourism. Besides, this border city could implement cross-regional cooperation with countries in northeastern Asia, turn itself into the tourist distribution center in the north of the core region of GCM tourist area, and develop into a brand of Changbai Mountain tourism.

3.3.3. Dunhua City, Baishan City, Tonghua City, Antu County, Fusong County, and Huichun City. Dunhua City, with a history of more than 1,000 years, is among the first batch of all-for-one tourism areas and top ten summer tourism cities in Jilin Province. Falling in the core region of GCM tourist area, the city achieved favorable TESI (0.5607) and TSCI (0.4754). Dunhua City belongs to the Northeast Asia Economic Circle and the radiation radius of Tumen River Economic Development Zone. In the planning for Changchun-Jilin-Tumen Pilot Area of Development and Opening, Dunhua City is a central link and strategic node between Changchun, hinterland of Jilin, and the frontier of Tumen River. It has certain advantages in geographical location, transportation, and market radiation. Therefore, the city should focus on all-for-one tourism, summer tourism, and cultural tourism.

Baishan City, which administers Jiangyuan District and Hunjiang District, rests in the hinterland of Changbai Mountains and belongs to the Changbai Mountains tourism economy circle and $3 \mathrm{~h}$ economic circles of Changchun and Shengyang. Famous for ecology, resources, and tourism, this city achieved fairly good TESI (0.4817) and TSCI (0.5592). It can serve as the tourist distribution center in the south of the core region of GCM tourist area and pursue ecological tourism, vacation tourism, and red tourism (centering on the Qidaojiang Conference Site).

Tonghua City administers Dongchang District, Erdaojiang District, and Tonghua County. The TESI (0.3861) and TSCI (0.5346) were general among the symbiosis units in the study area. The city is relatively far from Changbai Mountains scenic area and thus least driven by the scenic area. Fortunately, this major city in the Changbai Mountain Range boasts profound resources, including but not limited to health tourism resources (medical city), mountain tourism resources (mountainous city), ecological tourism resources (Baiji Peak Forest Park, Baijiyao National Forest Park, etc.), red tourism resources (Yuhuangshan Martyrs' Cemetry), and ice and snow tourism resources (Tonghua Ski Resort, Qianye Lake Ski Resort, etc.). In addition, Ji’an City, which belongs to Tonghua Prefecture, is famous for its southern beauty and the world heritage site of Koguryo 


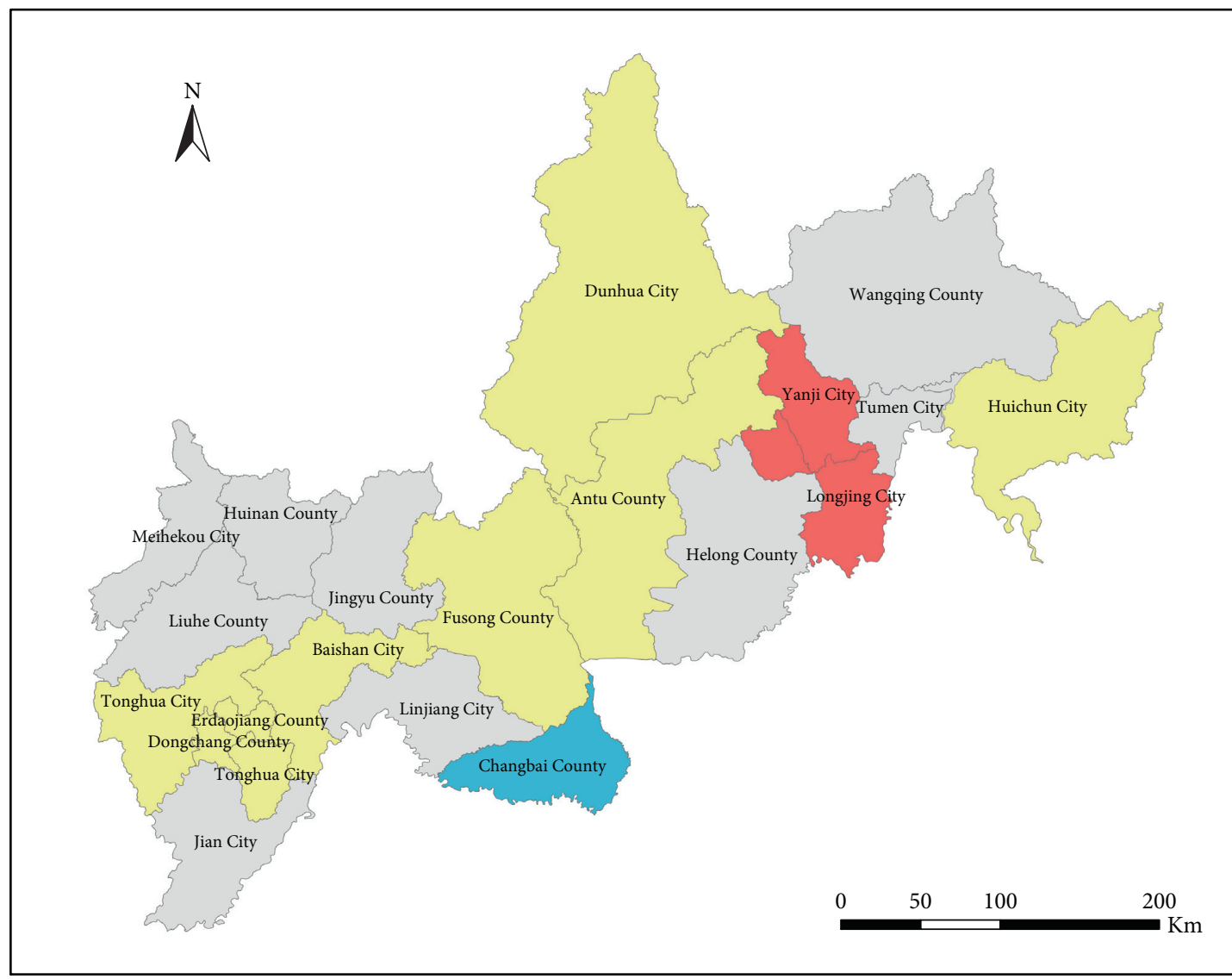

$0-0.0521$

$0.5209-0.7812$

$0.0522-0.5208$

Non-study area

Figure 2: Clustering results on the cities in the core region of CGM tourist area.

culture, although it is outside the core region of GCM tourist area. The opening of an expressway will make the city a driving engine to the comprehensive tourism development of Tonghua Prefecture. Therefore, Tonghua City could develop into another strategic node in the core region of GCM tourist area, focusing on the development of health tourism and mountain tourism.

Antu County (TESI: 0.3833; TSCI: 0.5281), and Fusong County (TESI: 0.3071; TSCI: 0.5991) are both in the hinterland of Changbai Mountains scenic area. The former is the northern gate of the area, and the latter is the western gate. Each year, many tourists pass through the two counties, but few stay in the local scenic spots. The two counties perform plainly on tourism economy scale and tourism symbiosis condition, for their tourism economy is greatly overshadowed by Changbai Mountains scenic area. Antu and Fusong should strive to develop into comprehensive service bases in the north and west of Changbai Mountains scenic area, while advancing all-for-one tourism, summer tourism, and health tourism.
Huichun City had relatively poor TESI (0.3025) and TSCI (0.4938). There are two main reasons for the poor performance: the long distance to Changbai Mountains scenic area and the lack of diversity of tourism resource development. This key border city of GCM tourist area, nicknamed the city of summer tourism, should join hands with Yanji City to develop summer tourism, with Fangchuan scenic spot at the core. Besides, it should actively construct a comprehensive service base for cross-border tourism between China, Russia, and North Korea.

Through cluster analysis, the symbiosis units should clarify their development goals and improve their overall symbiosis quality. The symbiosis, coexistence, and win-win between these units would build the tourism brand of GCM. In addition to the traditional tourism models of Changbai Mountains (e.g., sightseeing, ice and snow tourism, and ecological tourism), the symbiosis units should develop tourism in the light of their unique resources and promote the sustainable development of regional tourism (Table 6). 
TABLE 6: Tourism development orientations of core region of CGM tourist area.

\begin{tabular}{|c|c|c|}
\hline City & $\begin{array}{c}\text { Development } \\
\text { orientation }\end{array}$ & Development direction \\
\hline Yanji City & $\begin{array}{l}\text { Integrated tourism } \\
\text { Folk tourism } \\
\text { Summer tourism } \\
\text { Gourmet tourism } \\
\text { Shopping tourism }\end{array}$ & $\begin{array}{c}\text { Tourist distribution center in the north of GCM } \\
\text { City of Korean folk tourism } \\
\text { City of summer tourism } \\
\text { City of gourmet tourism } \\
\text { Shopping center for Chinese, North Korean, and Russian tourists }\end{array}$ \\
\hline Dunhua City & $\begin{array}{l}\text { All-for-one tourism } \\
\text { Summer tourism } \\
\text { Cultural tourism }\end{array}$ & $\begin{array}{l}\text { Strategic node of GCM tourism } \\
\text { Strategic node of Changchun-Jilin-Tumen tourism circle and Northeast Asia economic circle } \\
\text { City of summer tourism famous historical and cultural city of Jilin province beautiful county in } \\
\text { China }\end{array}$ \\
\hline Baishan City & $\begin{array}{l}\text { Integrated tourism } \\
\text { Red tourism }\end{array}$ & $\begin{array}{l}\text { Tourist distribution center in the south of GCM } \\
\text { Patriotism education base of Northeast China }\end{array}$ \\
\hline Tonghua City & $\begin{array}{l}\text { Integrated tourism } \\
\text { Health tourism } \\
\text { Mountain tourism }\end{array}$ & $\begin{array}{c}\text { Strategic node of GCM tourism } \\
\text { City of health tourism } \\
\text { Mountainous self-driving tour camp }\end{array}$ \\
\hline Antu County & $\begin{array}{l}\text { All-for-one tourism } \\
\text { Summer tourism } \\
\text { Mineral spring } \\
\text { tourism } \\
\text { Health tourism }\end{array}$ & $\begin{array}{l}\text { Comprehensive service base in the north of Changbai Mountains scenic area } \\
\text { Demonstration zone of all-for-one tourism } \\
\text { City of summer tourism home of mineral spring water in China } \\
\text { Health tourism base of green traditional Chinese medicine }\end{array}$ \\
\hline Fusong County & $\begin{array}{l}\text { All-for-one tourism } \\
\text { Summer tourism } \\
\text { Folk tourism } \\
\text { Ginseng tourism } \\
\end{array}$ & $\begin{array}{c}\text { Comprehensive service base in the west of Changbai Mountains scenic area demonstration zone } \\
\text { of all-for-one tourism } \\
\text { City of summer tourism } \\
\text { Product development of folk tourism: Shamanism } \\
\text { Wanliang Changbai Mountains ginseng market }\end{array}$ \\
\hline $\begin{array}{l}\text { Changbai } \\
\text { County }\end{array}$ & $\begin{array}{l}\text { All-for-one tourism } \\
\text { Border tourism } \\
\text { Folk tourism }\end{array}$ & $\begin{array}{c}\text { Comprehensive service base in the south of Changbai Mountains scenic area demonstration } \\
\text { zone of all-for-one tourism } \\
\text { Comprehensive service base for cross-border tourism of Chinese and North Korean tourists } \\
\text { Product development of folk tourism: Korean town }\end{array}$ \\
\hline Hunchun City & $\begin{array}{l}\text { Border tourism } \\
\text { Summer tourism }\end{array}$ & $\begin{array}{c}\text { Comprehensive service base for border and cross-border tourism of Chinese, Russian, and } \\
\text { North Korean tourists } \\
\text { City of summer tourism }\end{array}$ \\
\hline
\end{tabular}

\section{Conclusions}

With the proliferation of regional tourism, the core region of GCM tourist area should make the most of the important status of Jilin Province in the Belt and Road Initiative and actively implement China's strategy of regional coordinated development, while cooperating with the construction of the Changchun-Jilin-Tumen Pilot Area of Development and Opening. The destinations in our study area should interact with each other more frequently to achieve coexistence, symbiosis, and win-win, building the GCM tourism brand. Our research results provide theoretical support to the coordinated symbiosis in the core region of GCM tourist area, laying the basis for the formation of Changbaishan City. The future research will quantify the merits and defects of each symbiosis unit and further optimize the strategy for tourism development. The research scope will gradually extend from Changbai Mountains scenic area to the economic zones in the east and central east of Jilin Province, Harbin metropolitan area, Shengyang metropolitan area, and eastern Inner Mongolia, forming a regional cooperation circle in northeastern China. The ultimate goal is to create a Northeast Asia Economic Circle that seamlessly connects Northeast China with Inner Mongolia and foreign countries like Russia, North Korea, South Korea, and Japan.

\section{Data Availability}

The data used to support the findings of this study are available from the corresponding author upon request.

\section{Conflicts of Interest}

The authors declare that they have no conflicts of interest.

\section{Acknowledgments}

This work was supported by Social Science Research Project of Jilin Province (JJKH20210386SK): Study on the Development Effect of Leisure Agriculture from the Perspective of Farmers; Education Department of Jilin Province (JJKH20200001KJ): Study on the Development Effect of Leisure Agriculture from the Perspective of Farmers; Jilin Higher Education Association (JGJX2019B12): Practice and Exploration of Training Compound Tourism Talents for Rural Revitalization Strategy; and Jilin Provincial Department of Science and Technology Innovation Development Strategy Research Project: the Promotion of Tourism Accessibility around Changbai Mountain. 


\section{References}

[1] A. E. Douglas, Symbiotic Interaction, Oxford University Press, England, UK, 1994.

[2] P. F. Stringer and P. L. Pearce, "Toward a symbiosis of social psychology and tourism studies," Annals of Tourism Research, vol. 11 , no. 1, pp. 5-17, 1984.

[3] D. Getz and T. B. Jamal, "The environment-community symbiosis: a case for collaborative tourism planning," Journal of Sustainable Tourism, vol. 2, no. 3, pp. 152-173, 1994.

[4] Z. X. Tang, Y. F. Ma, and J. Y. Xiao, "The regional cooperated study of inbound tourism in Qingzang area based on the theory of coexistence," Qinghai Journal of Ethnology, vol. 23, no. 1, pp. 100-105, 2012.

[5] H. Wu and C. L. Gu, "The cooperation-competition of regional tourism based on the symbiosis theory-a case study on huaihai economic region," Economic Geography, vol. 1, pp. 104-109, 2004.

[6] Z. Zheng and W. H. Liu, "Tourism competition and cooperation in Poyang lake ecological economic zone based on symbiosis theory," Journal of Finance and Economics, vol. 6, pp. 88-89, 2010.

[7] S. Candia, F. Pirlone, and I. Spadaro, "Integrating the carrying capacity methodology into tourism strategic plans: a sustainable approach to tourism," International Journal of Sustainable Development and Planning, vol. 15, no. 3, pp. 393-401, 2019.

[8] R. A. Castanho, G. Couto, P. Pimentel, C. Carvalho, Á. Sousa, and M. da Graça Batista, "Analysing the public administration and decision-makers perceptions regarding the potential of rural tourism development in the Azores region," International Journal of Sustainable Development and Planning, vol. 16, no. 4, pp. 603-614, 2021.

[9] J. X. Ji, "On the interest coordination mechanism in the ancient-village tourism based on the symbiosis theory-a Case study of Xiamei village," Journal of Agro-Forestry Economics and Management, vol. 10, no. 2, pp. 124-130, 2011.

[10] U. Claude, "Predicting tourism demands by google trends: a hidden markov models based study," Journal of System and Management Sciences, vol. 10, no. 1, pp. 106-120, 2020.

[11] R. Mekvabidze, "Global perspectives of hotel services and hospitality management study: a case of Georgia," Journal of System and Management Sciences, vol. 8, no. 3, pp. 1-25, 2018.

[12] Y. M. Ma, Study on the Mechanism of Symbiosis and Xinxiang Southern Taihang Development of Rural Tourism in the Interests of the Game, Henan Normal University, Xinxiang, China, 2017.

[13] Z. X. Tang and M. L. Liu, "Analysis of multiple-agents' symbiotic patterns of tourism community governance: based on the case of two typical communities of Qinghai province," Human Geography, vol. 33, no. 6, pp. 125-131, 2018.

[14] Q. Q. Wang, Study on Symbiotic Relationship among Stakeholders of Da-Mo-Yu Rural Tourism, Yunnan University, Kunming, China, 2019.

[15] X. L. Lu, Z. W. Sun, and S. M. Ma, “The symbiotic relationship and the polycentric cooperative development countermeasures of urban tourism in Beijing-Tianjin-Hebei metropolitan," Economic Geography, vol. 36, no. 4, pp. 181-187, 2016.

[16] H. Y. Su and C. L. Chen, "Polycentric symbiosis of regional city tourism in Pearl river delta in the context of GuangdongHongkong-Macao greater bay area construction," Journal of China West Normal University (Natural Sciences), vol. 41, no. 3, pp. 322-330, 2020.
[17] F. W. Wei, R. J. Huang, and P. F. Shi, "Study on the cooperative development of regional urban tourism based on the symbiosis theory in Guangxi," Journal of Northwest Normal University (Natural Science), vol. 56, no. 3, pp. 118-126, 2020.

[18] Y. Yang, Research on the Coordinated Development of Tourism Multi-Centers in Wuhan Metropolitan Area Based on Symbiosis Theory, Yunnan University of Finance and Economics, Kunming, China, 2017.

[19] G. Q. Ma and H. L. Wang, "The coordinated development of tourism industry in Lanzhou city group from the perspective of symbiosis theory," Urban Problems, vol. 4, pp. 65-71, 2018.

[20] W. Ni and Y. H. Wei, "The ways and measures to realize the sustainable utilization of tourism resources in Changbai mountain," Economic Review Journal, vol. 11, pp. 62-63, 2002.

[21] D. W. Sun, T. Chen, and Y. Jiang, "The integrated development of tourism resources and eco-environment protection in Changbai mountain natural reserve," Journal of Northeast Forestry University, vol. 5, pp. 97-99, 2005.

[22] G. C. Cao, "Analysis on the development of eco-tourism of Changbai mountain," Journal of Northeast Normal University (Natural Science Edition), vol. 40, no. 4, pp. 147-151, 2008.

[23] S. Sun, "Study on sustainable development of ecotourism in Changbai mountain," China Journal of Commerce, vol. 23, pp. 161-162, 2011.

[24] G. H. Yan, "The development path of Changbai mountain ecotourism from the perspective of ecological civilization," Environmental Protection, vol. 41, no. 24, pp. 65-66, 2013.

[25] M. J. Liu, S. J. Wang, and Y. J. Sheng, "Sustainable development of tourism in northern part of Changbai mountain," Taxation and Economy, vol. 3, pp. 104-109, 2015.

[26] S. Q. Dai and Y. D. Li, "Study on shaman cultural tourism development in Changbai mountain area," Manchu Minority Research, vol. 4, pp. 118-121, 2014.

[27] H. Zhang and M. Xia, "Research on tourism spatial structure of Anhui province-based on tourism centrality degrees and tourism economic contact," Economic Geography, vol. 31, no. 12, pp. 2116-2121, 2011.

[28] T. Hu, Study on Measurement and Structure of Regional Symbiosis System of Tourist Destinations-Taking Western Hunan for Example, Hunan Normal University, Changsha, China, 2019. 